UCRL-ID-132991

\title{
Scoping the Parameter Space for Demo and Engineering Test Facility (ETF)
}

\author{
Wayne R. Meier
}

January 19, 1999

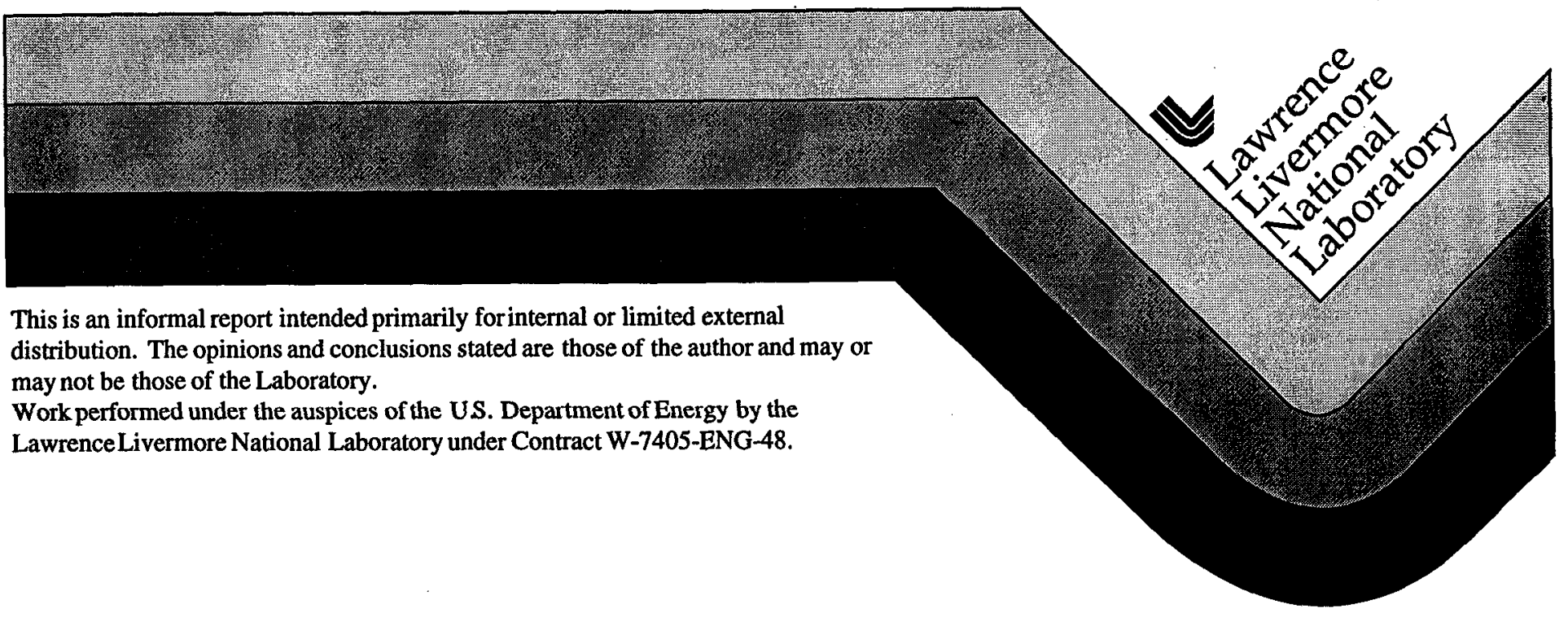




\section{DISCLAIMER}

This document was prepared as an account of work sponsored by an agency of the United States Government. Neither the United States Government nor the University of California nor any of their employees, makes any warranty, express or implied, or assumes any legal liability or responsibility for the accuracy, completeness, or usefulness of any information, apparatus, product, or process disclosed, or represents that its use would not infringe privately owned rights. Reference herein to any specific commercial product, process, or service by trade name, trademark, manufacturer, or otherwise, docs not necessarily constitute or imply its endorsement, recommendation, or favoring by the United States Government or the University of Califomia. The views and opinions of authors expressed herein do not necessarily state or reflect those of the United States Government or the University of Califomia, and shall not be used for advertising or product endorsement purposes.

This report has been reproduced directly from the best available copy.

Available to DOE and DOE contractors from the Office of Scientific and Technical Information P.O. Box 62, Oak Ridge, TN 37831

Prices available from (615) 576-8401, FTS 626-8401

Available to the public from the

National Technical Information Service

U.S. Department of Commerce

5285 Port Royal Rd.

Springfield, VA 22161 
ICF Applications Group

Mail Stop L-446

Phone: 422-8536, Fax: $422-7390$

Email: wmeier@ IInl.gov

\section{Memorandum}

Aug. 23, 1998

Jan. 12, 1999, Rev. 1

WRM-98-012

To: $\quad$ R. Bangerter, S. Bodner, M. Campbell, H. Powell

Copies: J. Barnard, A. Faltens, A. Friedman, E. Lee, J. Lindl, G. Logan, C. Marshall, R. Moir, S. Payne, J. Perkins

From: Wayne Meicr

Subject: Scoping the Parameter Space for Demo and ETF

\section{Introduction}

In our IFE development plan, we have set a goal of building an Engineering Test Facility (ETF) for a total cost of $\$ 2 \mathrm{~B}$ and a Demo for \$3B. In Mike Campbell's presentation at Madison, we included a viewgraph with an example Demo that had 80 to $250 \mathrm{MW}_{\mathrm{e}}$ of net power and showed a plausible argument that it could cost less than $\$ 3 \mathrm{~B}$. In this memo, I examine the design space for the Demo and then briefly for the ETF. Instead of attempting to estimate the costs of the drivers, I pose the question in a way to define R\&D goals:

As a function of key design and performance parameters, how much can the driver cost if the total facility cost is limited to the specified goal?

The design parameters examined for the Demo included target gain, driver energy, driver efficiency, and net power output. For the ETF, the design parameters are target gain, driver energy, and target yield. The resulting graphs of allowable driver cost determine the goals that the driver R\&D programs must seek to meet.

In this memo, I will refer to the figures contained in the attached Mathcad document, which also includes all the assumptions.

\section{Parameter Ranges Considered} Target Gain

Figure 1 (p. 2 of Mathcad attachment) shows the target gain curves used in the analysis. The laser curves were fit to those shown in Fig. 10 of Ref. 1. While the isentrope parameter $\alpha$ is used as the designator, the range of gains from $\alpha=1$ to 3 can be thought of as way to represent uncertainty and different designs (e.g., effects of 2D calculations, improvements from laser zooming, use of indirect drive, etc.). There are two curves for the heavy ion driver. The base case has the same functional form and shape as the $\alpha=3$ curve, but is degraded by $10 \%$ so that it passes through the Tabak/Callahan-Miller distributed radiator point design $(\mathrm{G}=73$ at $\mathrm{E}=5.9 \mathrm{MJ})$. 
Preliminary results by Callahan-Miller show that gains higher than the base case are possible using close-coupled target designs. A second heavy-ion target gain curve fits results for the close-coupled target designs.

\section{Driver Energy}

The range from 1-10 MJ was examined, but most interesting cases are less than $5 \mathrm{MJ}$.

\section{Driver Efficiencies}

Driver efficiencies ranged from 5 to $10 \%$ for lasers and 15 to $30 \%$ for accelerators.

\section{Net Power}

I looked at three cases: 100,300 and $500 \mathrm{MW}_{\mathrm{e}}$.

\section{Costs for Non-driver Components.}

I've made very simple costing assumptions for the cost of Demo and ETF facility costs derived from previous power plant studies. ${ }^{2,3}$ Fusion components (chamber, target factory, heat transfer system, and buildings) are costed at $\$ 1000 / \mathrm{kW}_{\mathrm{t}}$ (same as Wisconsin presentation). This is about 1.5 times upper end of plant costs from IFE power plant studies. Power generation equipment (turbine plant equipment, electrical plant equipment and associated buildings) cost scaling is taken from the Osiris study (most conservative case); it is equal to $\$ 550 / \mathrm{kW}_{\mathrm{e}}$ at $1100 \mathrm{MW}_{\mathrm{e}}$ and scales as (total electric power) ${ }^{0.6}$.

\section{Results}

\section{Allowable Laser Driver Cost for Different Net Powers}

Figure 4 (p. 8) shows the allowable laser driver total cost (expressed in 100's of dollars per joule) as a function driver energy for net powers of 100,300 and $500 \mathrm{MW}_{\mathrm{e}}$ assuming a driver efficiency of $7 \%$ and the $\alpha=2$ gain curve. (Note that "total cost" includes all the indirect costs; allowable direct costs would be about a factor of two lower.) The smaller the net power of the Demo, the higher the allowable driver cost to stay within the \$3B limit since less money is spent on the plant components. On the other hand, the higher the net power of the Demo, the closer its cost of electricity (COE) will be to levels that can be scaled convincingly to competitive energy. The curves show peaks in allowed driver cost at 1.6, 2.0 and $\sim 3 \mathrm{MJ}$ for $\mathrm{P}_{\text {net }}=100,300$, and $500 \mathrm{MW}_{e}$, respectively. At driver energies below these peaks, the target gain decreases rapidly and recirculating power increases (see Fig. 2, p. 5) resulting in a large plant size and cost to produce the desired net power; this leaves less money for the driver. Beyond the peaks, there is no benefit, in terms of increased gain and reduced recirculating power, of building a larger laser. (This is true unless the economy of scale for the driver is such that the $\$ / \mathrm{J}$ is falling faster than the allowable $\$ / J$ with increasing driver energy.)

Don't be too quick to conclude that we want a small net power for the Demo. The resulting cost of electricity is $59.3,19.8$ and 11.9 cents/kW $/ \mathrm{k}_{\mathrm{h}}$ for the 100,300 and $500 \mathrm{MWe}$ cases, respectively. Since the Demo will be the last government funded facility and must demonstrate the economic attractiveness for IF power, this is an important consideration. In the future, I'll address the potential of multi-unit plants sharing a single driver to show the potential of these designs. 
Figure 5 (p. 9) is the same as Fig. 4 except I have added the rep-rate required to generate the specified net power. This curve can be used to answer the question of what driver energy is required if rep-rate is limited and what the allowable driver cost is under such a constraint. For example, the $300 \mathrm{MW}_{\mathrm{e}}$ case has a peak allowable driver cost of $\$ 640 / \mathrm{J}$ at a driver energy of $2 \mathrm{MJ}(\sim \$ 1.3 \mathrm{~B}$ total) corresponding to a rep-rate of $8.6 \mathrm{~Hz}$. If the rep-rate was limited to $5 \mathrm{~Hz}$, a $2.5 \mathrm{MJ}$ driver would be needed to generate $300 \mathrm{MWe}$, and the allowable cost would be $\$ 600 / \mathrm{J}$ ( $\$ 1.5 \mathrm{~B}$ total).

\section{Allowable Laser Driver Cost for Different Target Gain Curves}

Figure 6 (p. 10) is similar to Fig. 5 except it shows results for different target gain curves with $\mathrm{P}_{\text {net }}$ fixed at $300 \mathrm{MW}_{\mathrm{e}}$. If $\alpha=1$ target performance could be achieved, a $5 \mathrm{~Hz}, 300 \mathrm{MW}_{\mathrm{e}}$ Demo could be built using a $1.5 \mathrm{MJ}$ driver costing up to $\$ 1100 / \mathrm{J}$ total. With $\alpha=3$ type performance, the allowable driver cost is about $\$ 275 / \mathrm{J}$ over the range of 3.5 to $4.5 \mathrm{MJ}$ ( 7 to $4 \mathrm{~Hz}$ ).

\section{Allowable Laser Driver Cost for Different Driver Efficiencies}

Figure 7 (p. 11) shows the impact of varying the laser efficiency while holding the net power constant at $300 \mathrm{MW}_{\mathrm{e}}$. As expected, higher efficiency lasers can be more expensive under the assumption of a fixed total Demo cost since the recirculating power is lower, and thus the size and cost of the plant is smaller. Conversely, lower efficiency lasers are allowed if the cost per joule is low enough.

\section{Allowable HIB Driver Cost for Different Net Powers}

Figure 8 (p. 12) shows the allowable heavy ion driver cost and rep-rate as a function of driver energy for net powers of 100,300 , and $500 \mathrm{MW}_{\mathrm{c}}$ assuming the base case gain curve and a driver efficiency of $20 \%$. The trends are very similar to the laser driver (see Fig. 5) with the $300 \mathrm{MW}_{\mathrm{e}}$ case also peaking near $2 \mathrm{MJ}$. The allowable costs are somewhat higher than the laser case in Fig. 5, indicating that the higher driver efficiency more than offsets the lower target gain. The target yield at a given energy is significantly lower however (see Fig. 3, p. 6) so the rep-rate required for a specified net power is higher than in the laser case $(17.7 \mathrm{~Hz}$ vs. $8.6 \mathrm{~Hz}$ at $\mathrm{E}=2 \mathrm{MJ})$. If the rep-rate for the $300 \mathrm{MW}_{\mathrm{e}}$ case is limited to $5 \mathrm{~Hz}$, a $3.4 \mathrm{MJ}$ driver would be needed with a maximum total cost of $\$ 510 / \mathrm{J}$, significantly lower than the $\$ 730 / \mathrm{J}$ allowed at $2 \mathrm{MJ}$.

\section{Allowable HIB Driver Cost for Different Gain Curves}

Figure 9 (p. 13) shows the effect of using the close-coupled HIB target gain curve. The trends are similar to the laser case (e.g., going from $\alpha=2$ to $\alpha=1$ in Fig. 6.). The benefit of the higher gain curve decreases with increasing driver energy; at $2 \mathrm{MJ}$, an additional $\$ 200 / \mathrm{J}$ would be allowed, while at $3 \mathrm{MJ}$, the additional allowance is less than $\$ 70 / \mathrm{J}$. With the close-coupled target, the rep-rate for $300 \mathrm{MW}_{\mathrm{e}}$ falls to $5 \mathrm{~Hz}$ at a driver energy of $\sim 1.7 \mathrm{MJ}$ corresponding to an allowable driver cost of $\$ 1100 / J$.

\section{Allowable HIB Driver Cost for Different Driver Efficiencies}

Figure 10 (p. 14) shows the sensitivity of the results to variations in the HIB driver efficiency over the range of 15 to $30 \%$. As with the laser, the sensitivity to changes in 
driver efficiency is greater at lower driver energy where the gain is lower. At $2 \mathrm{MJ}$, increasing the driver efficiency from 20 to $30 \%$ would allow an additional $\sim \$ 110 / \mathrm{J}$, while at $3 \mathrm{MJ}$ the additional allowance is only $\sim \$ 40 / \mathrm{J}$.

\section{ETF Results}

The ETF is characterized more by the yield per shot than the power, although it will test average power operation at least for limited periods of time. The ETF is assumed to dump its thermal power and therefore does not require the electric power generating equipment and associated costs as with the Demo. Recall that the total cost goal here is $\$ 2 \mathrm{~B}$. Here again we ask, for a given size ETF, what is the allowable driver cost?

Figure 11 (p. 15) shows driver energy required to achieve a specified yield for the different laser and HIB gain curves. In previous studies, we showed that small scale chamber test could be done at the $\sim 30 \mathrm{MJ}$ yield level. ${ }^{4}$ This would require a driver energy of 0.8 to $2 \mathrm{MJ}$ depending on the type of driver and gain curve.

Figure 12 (p. 16) shows the allowable ETF driver cost as a function of the desired yield for the various drivers and gain curves. At $30 \mathrm{MJ}$, the allowable total costs are quite large $(>\$ 1000 / \mathrm{J})$. Even at $60 \mathrm{MJ}$, the allowable costs are all $>\$ 500 / \mathrm{J}$. This bodes well for the possibility that future ETF designs can meet the $<\$ 2 B$ TPC limit.

\section{Conclusions}

A broad range of parameters have been examined for the Demo and ETF with the idea of determining what is needed in terms of driver cost in order to meet the cost goals that we've expressed. This memo is intended to initiate discussion on the subject and should be considered preliminary. At this point, nothing is set in stone and additional case can easily be run.

Some of the questions we need to address are:

1) How close does the Demo have to come to being economically competitive, and will replicating these small chambers in a multi-unit plant get us close enough?

2) What power levels allow reasonable cost goals for the drivers?

3) Multi-unit power plants will help meet the COE and total development cost goals through upgrades. What are the beam transport, beam switchyard, and final optics costs per chamber allowed to support multiple chambers?

\section{References}

1. S. E. Bodner et al., 'Direct-Drive Laser Fusion; Status and Prospects," NRL report, NRL/MR/6730-98-8113 (March 13, 1998)

2. W. R. Meier, et al., "Osiris and Sombrero Inertial Fusion Power Plant Designs, W.J. Schafer Associates report, WJSA-92-01, DOE/ER/54100-1 (1992)

3. R. W. Moir, "Improvements to the HYLIFE-II Inertial Fusion Power Plant Design," Fusion Technol. 26 (1994) 1169-1177.

4. W. R. Meier and W. J. Hogan, "An Integrated Test Facility for Inertial Fusion Energy Using Heavy Ion Drivers," Proc. 15 IEEE/NPSS Sym. on Fusion Engineering (Hyannis, MA, Oct. 11-15, 1993) 0-7803-1412-3, p. 1001 (1994). 
Demo Parameter Study

$8 / 22 / 98$

1/12/99 Revised to include close-coupled target gain for heavy ion driver

Wayne Meier, LLNL

(925) 422-8536/ wmeier@Ilnl.gov

Set input assumptions for Demo plant:

fa := $0.04 \quad$ Auxiliary power fraction (excludes driver power requirements)

$M:=1.1 \quad$ Energy multiplication factor (typical factor)

$\varepsilon:=0.43 \quad$ Thermal conversion efficiency (Typical of HYLIFE-II and Osiris)

Target Gain

Gain curves for $\alpha=1,2,3$ for lasers fit to Bodner et al. APS paper in 1-2 MJ range.

Base case heavy ion gain curve goes through Tabak, Callahan-Miller design ( $E=5.9 \mathrm{MJ}$, $Y=430 \mathrm{MJ}$ ). A second HIB case is for close-coupled target designs.

Laser curves for $\alpha=1,2,3$ :

$$
\begin{array}{ll}
\mathrm{G1}(E):=70+130 \cdot \ln (E) & \mathrm{G} 1(2)=160.1 \\
\mathrm{G} 2(E):=16+78 \cdot \ln (E) & \mathrm{G} 2(2)=70.1 \\
\mathrm{G} 3(E):=2.5+44 \cdot \ln (E) & \mathrm{G} 3(2)=33
\end{array}
$$

HIB driver curves (base case and close-coupled target design):

$$
\begin{array}{ll}
\mathrm{G} 4(\mathrm{E}):=0.9 \cdot \mathrm{G} 3(\mathrm{E}) & \mathrm{G} 4(5.9)=72.5 \\
\mathrm{G} 5(\mathrm{E}):=59.6+61.5 \cdot \ln (\mathrm{E}) & \mathrm{G} 5(3.3)=133
\end{array}
$$

Select a gain curve:

$$
\begin{aligned}
& a=1 \rightarrow \alpha=1 \\
& a=2 \rightarrow>\alpha=2 \\
& a=3 \rightarrow \alpha=3 \\
& a=4->\text { HIB base case } \\
& a=5 \rightarrow \text { HIB close-coupled target design } \\
& G a(a, E):=\text { if }(a<2, G 1(E),(\text { if }(a<3, G 2(E),(\text { if }(a<4, G 3(E), G 4(E)))))) \\
& G(a, E):=\text { if }(a<5, G a(a, E), G 5(E))
\end{aligned}
$$

Define plot ranges: $\quad E 1:=1,1.5 . .10 \quad E 4:=1.5,2.0 . .10 \quad E 5:=2.5,3 . .10$ 
Fig. 1. Target gain curves

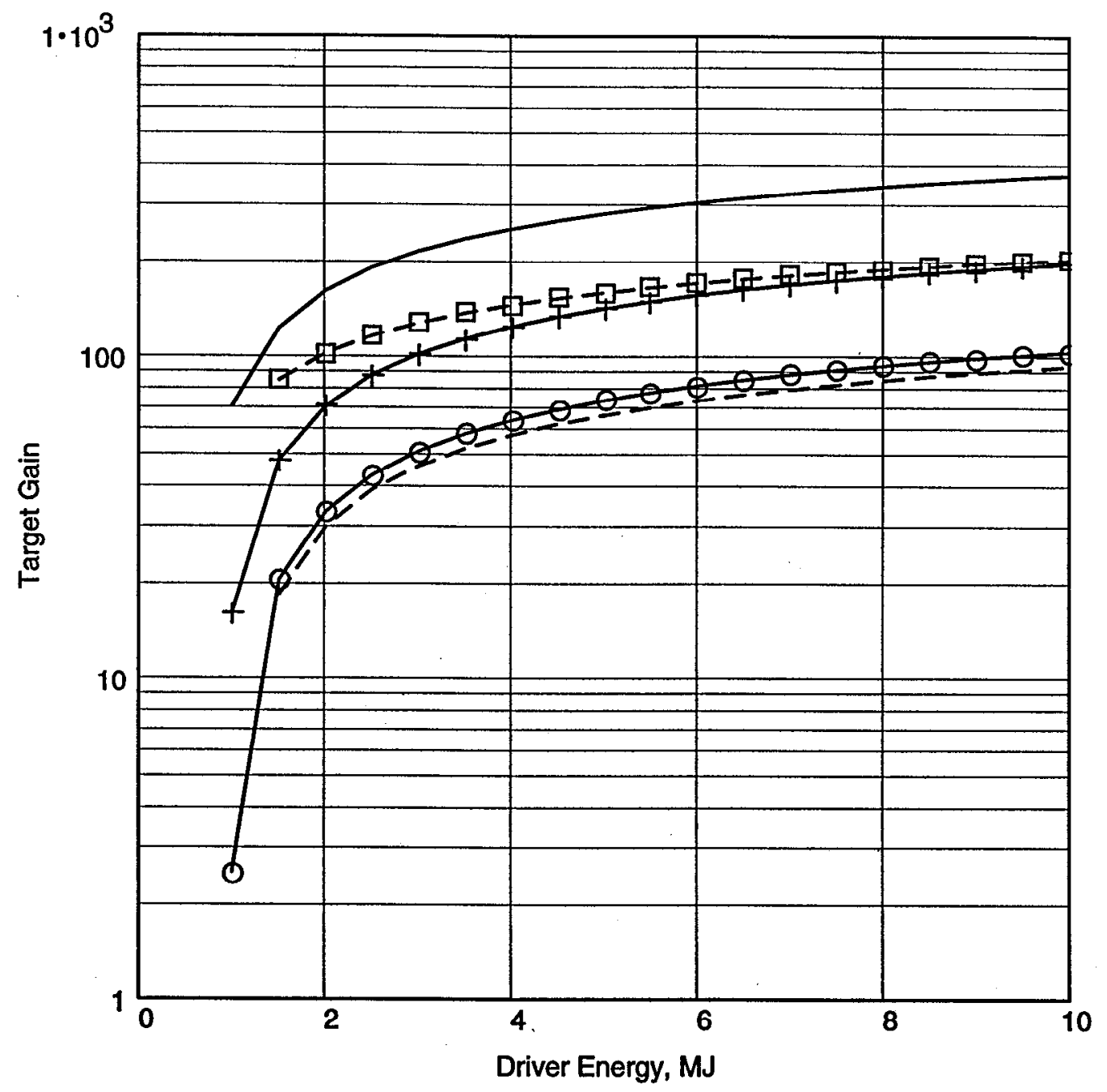

- Laser: alpha $=1$

+ Laser: alpha $=2$

- Laser: alpha $=3$

- HIB: base case

다 HIB: close-coupled 
The following variables are used:

$a=$ target gain designator

$E=$ driver energy, $M J$

$\eta=$ driver efficiency

$\mathrm{Pn}=$ net power, $\mathrm{MWe}$

Define some parameters for example calculations:

Driver energy, MJ

Eo := 2

Laser efficiencies

$\eta 5:=0.05$

$\eta 7:=0.07$

$\eta 10:=0.10$

Heavy ion driver efficiencies

$\eta 15:=0.15$

$\eta 20:=0.20$

$\eta 30:=0.30$

Net electric power, $\mathrm{MWe}$

Pno : $=300$

When net power is specified, rep-rate is a calculated value (normal mode).

If rep-rate is fixed, net power will vary.

Example rep-rate for fixed rep-rate case, $\mathrm{Hz}$

RRo := 5

Thermal power, MWt

$$
\operatorname{Pt}(a, E, \eta, P n):=\frac{P n}{\varepsilon \cdot\left(1-f a-\frac{1}{\eta \cdot G(a, E) \cdot M \cdot \varepsilon}\right)}
$$

Example calculation:

$\operatorname{Pt}(2$, Eo $, \eta 7, P n o)=1319$

If fixed rep-rate, use following

$\operatorname{Pt}(a, E, \eta, P n):=R R o \cdot E \cdot G(a, E) \cdot M a$ 
Rep-rate, $\mathrm{Hz}$

$R R(a, E, \eta, P n):=\frac{P t(a, E, \eta, P n)}{E \cdot G(a, E) \cdot M}$

$R R(2$, Eo $, \eta 7, P n o)=8.56$

Yield, MJ

$Y(a, E):=E \cdot G(a, E)$

$Y(2$, Eo $)=140.1$

Fusion power, MW

$\operatorname{Pf}(a, E, \eta, P n):=Y(a, E) \cdot R R(a, E, \eta, P n) \quad P f(2, E o, \eta 7, P n o)=1199.1$

Gross (total) electric power, MWe

$P g(a, E, \eta, P n):=P t(a, E, \eta, P n) \cdot \varepsilon$

$\mathrm{Pg}(2$, Eo $, \eta 7, \mathrm{Pno})=567.2$

Auxiliary power, MWe

$\operatorname{Paux}(a, E, \eta, P n):=f a \cdot P g(a, E, \eta, P n)$

$\operatorname{Paux}(2$, Eo $, \eta 7, \operatorname{Pno})=22.7$

Driver power, MWe

$\operatorname{Pd}(a, E, \eta, P n):=E \cdot \frac{R R(a, E, \eta, P n)}{\eta} \quad \operatorname{Pd}(2, E o, \eta 7, P n o)=244.5$

Calculated net power, MWe (needed when rep-rate is fixed)

$\operatorname{Pnet}(a, E, \eta, P n):=P g(a, E, \eta, P n)-P d(a, E, \eta, P n)-P a u x(a, E, \eta, P n)$

Pnet $(2$, Eo,$\eta 7$, Pno $)=300$

Recirculating power fraction for driver

$\operatorname{RPF}(a, E, \eta, P n):=\frac{P d(a, E, \eta, P n)}{\operatorname{Pg}(a, E, \eta, P n)} \quad \operatorname{RPF}(2, E o, \eta 7, P n o)=0.43$ 
Fig. 2. Driver recirculating power fraction vs. driver energy for different gain curves Laser efficiency $=7 \%$

HIB efficiency $=20 \%$

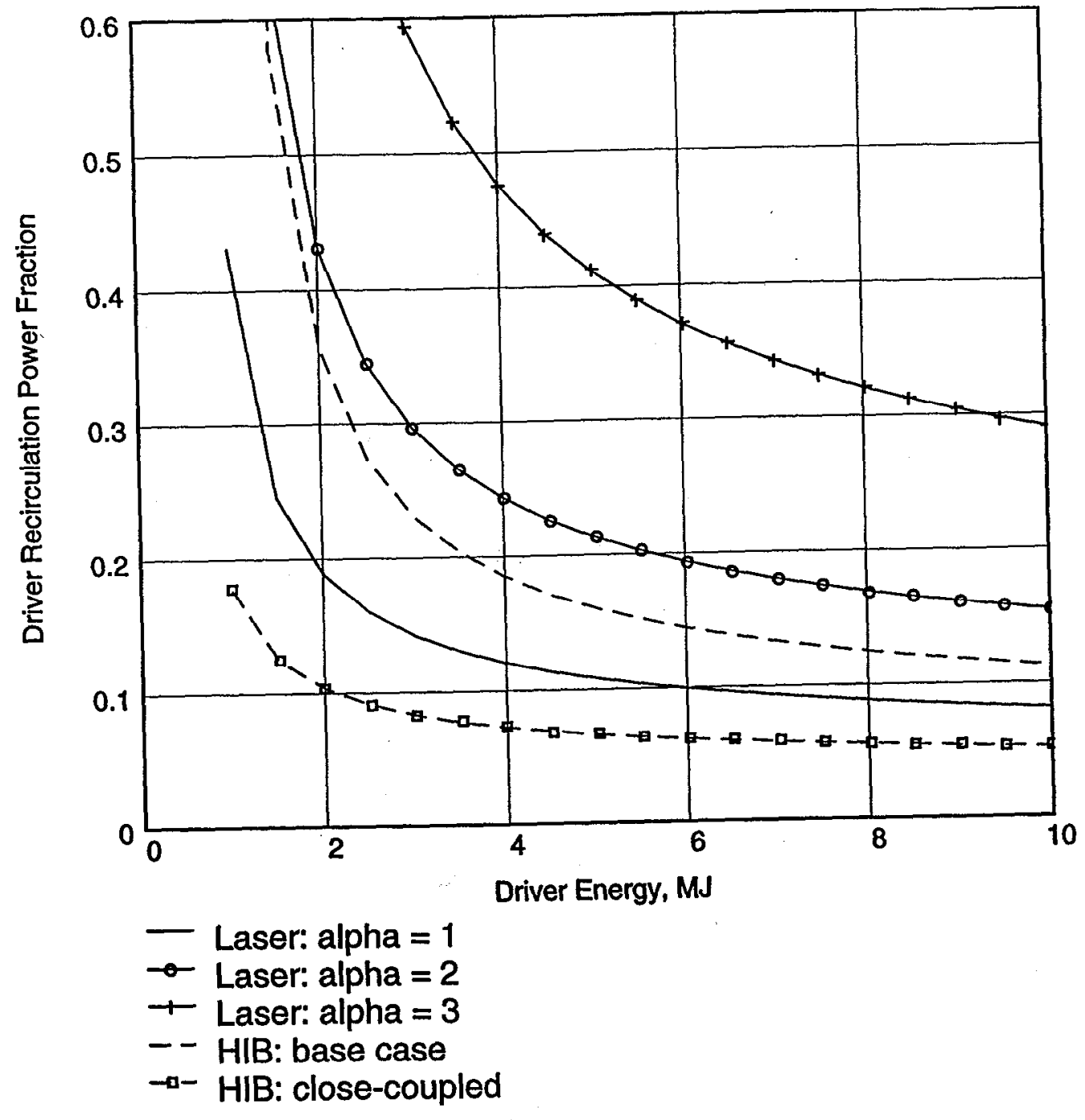


Fig. 3. Yield vs. driver energy for various gain curves

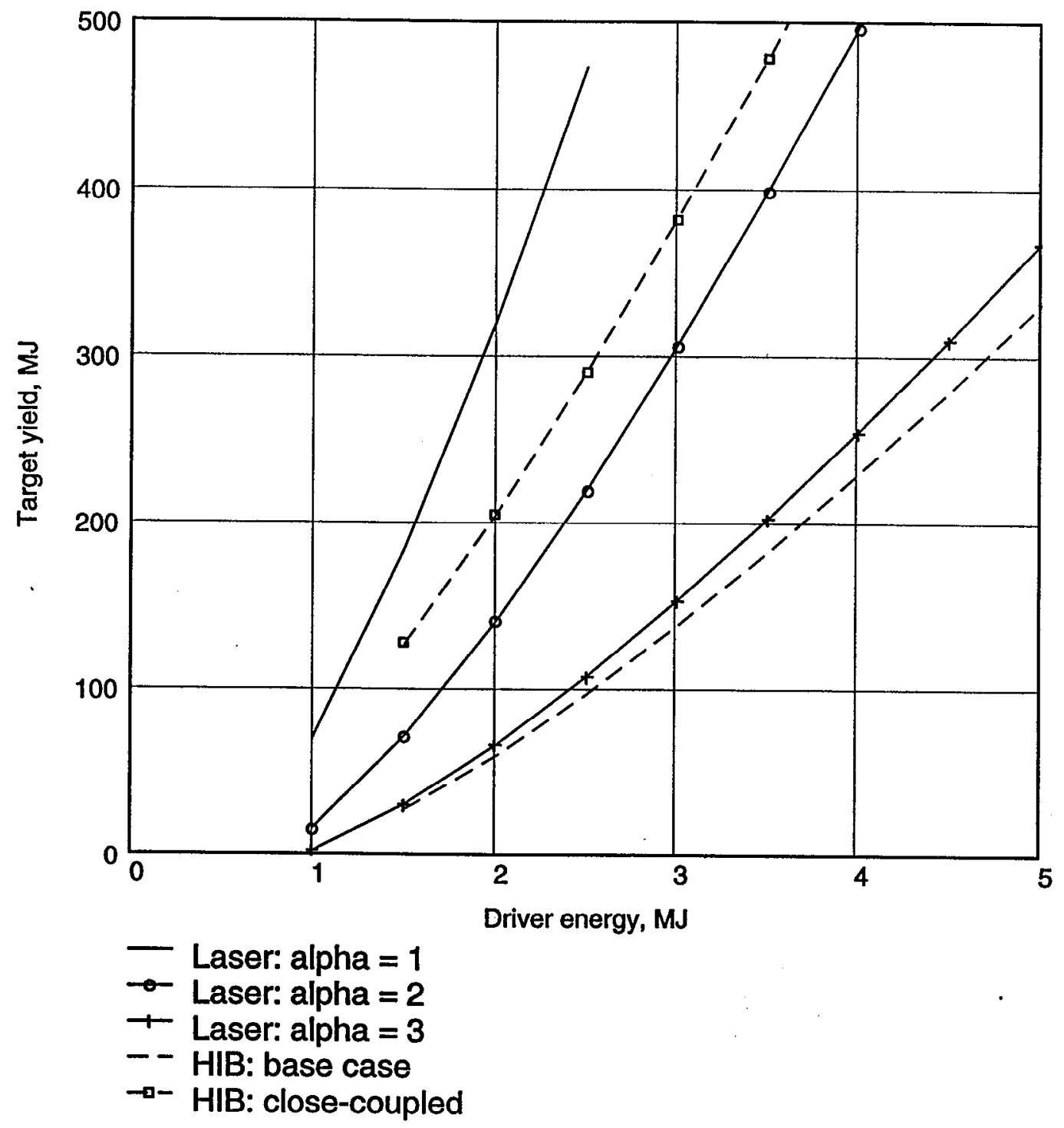


Fusion Component Costs.

Includes chamber, target factory, main heat transfer system, buildings

Total cost $=\$ 1000 / \mathrm{kWt}=\$ 106 / \mathrm{MWt}=1.5$ times upper end of costs from

power plant studies

Unit cost, \$/ MWt

UCfc $:=10^{6}$

Total cost, \$

$\operatorname{Cfc}(a, E, \eta, P n):=U C f c \cdot \operatorname{Pt}(a, E, \eta, P n) \quad \operatorname{Cfc}(2, E o, \eta 7, P n o)=1.32 \cdot 10^{9}$

Turbine and Electric Plant Equipment (plus associated buildings).

$\$ 550 / \mathrm{kWe}$ at $1100 \mathrm{MWe}$. Scales as Power 0.6

Cost at $1100 \mathrm{MWe}, \$$

Cteo $:=0.55 \cdot 10^{6} \cdot 1100$

$\operatorname{Cte}(a, E, \eta, P n):=\operatorname{Cteo} \cdot\left(\frac{P g(a, E, \eta, P n)}{1100}\right)^{0.6} \quad \operatorname{Cte}(2, E o, \eta 7, P n o)=4.07 \cdot 10^{8}$

Allowable driver cost is $\$ 3 \mathrm{~B}$ minus the other costs, $\$$

Cdallow $(a, E, \eta, P n):=3 \cdot 10^{9}-\operatorname{Cfc}(a, E, \eta, P n)-\operatorname{Cte}(a, E, \eta, P n)$

Cdallow $(2$, Eo,$\eta 7$, Pno $)=1.27 \cdot 10^{9}$

Total allowed cost for driver (express in 100's $\$ / \mathrm{J}$ )

$\operatorname{Cdpj}(a, E, \eta, P n):=\frac{\operatorname{Cdallow}(a, E, \eta, P n)}{E \cdot 10^{6}} \cdot 0.01$

Define plot range

$\mathrm{Eg}:=1.4,1.6 . .5$ 
Fig. 4. Allowable laser driver total cost (100's $\$ / J)$ for:

Total Demo cost $=\$ 3 \mathrm{~B}$

Target $\alpha=2$

Driver efficiency $=7 \%$

Net power $=100,300,500 \mathrm{MWe}$

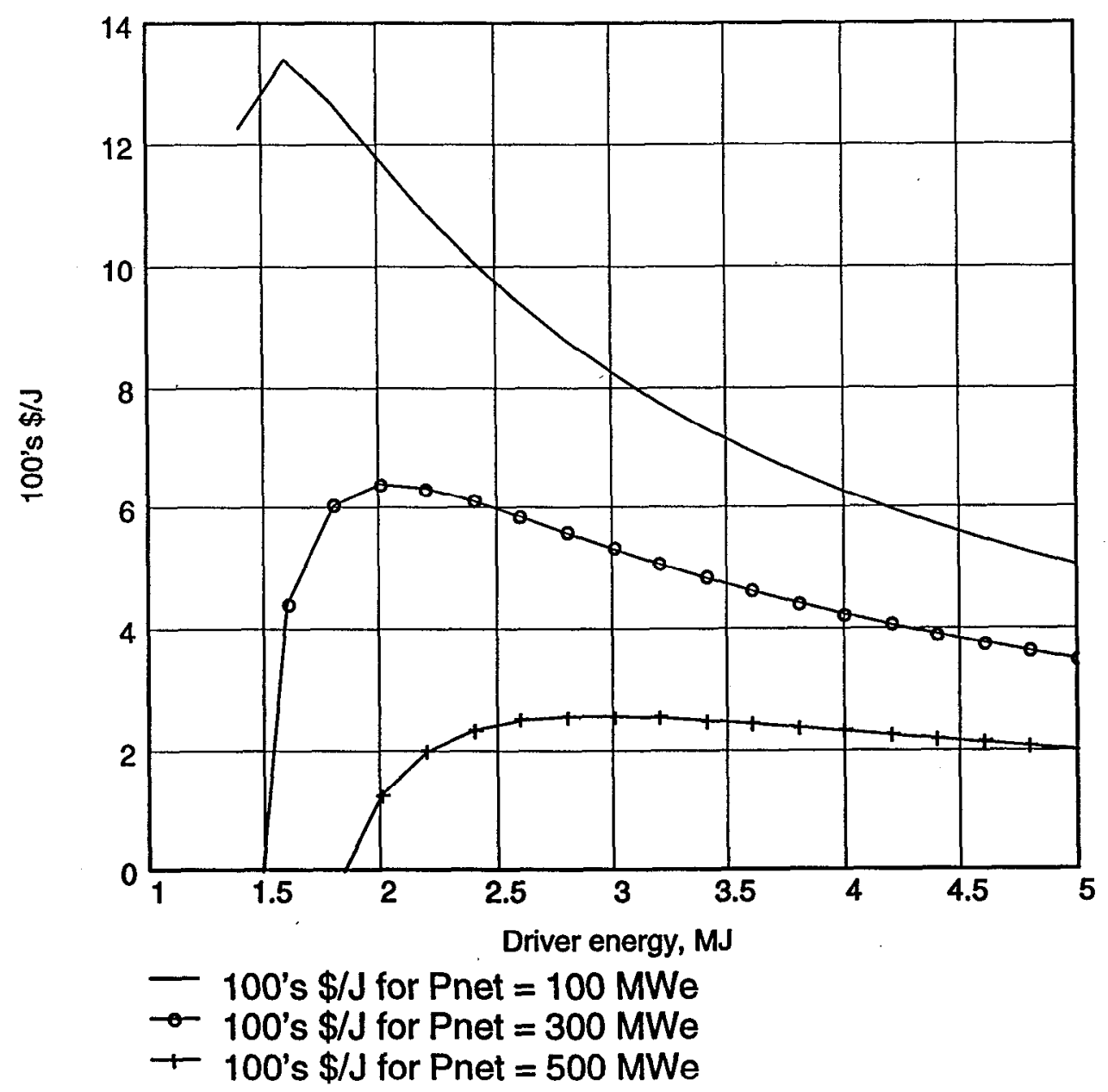


Fig. 5. Allowable laser driver total cost (100's $\$ / J)$ and rep-rate $(\mathrm{Hz})$, for:

Total Demo cost $=\$ 3 \mathrm{~B}$

Target $\alpha=2$

Driver efficiency $=7 \%$

Net power $=100,300,500 \mathrm{MWe}$

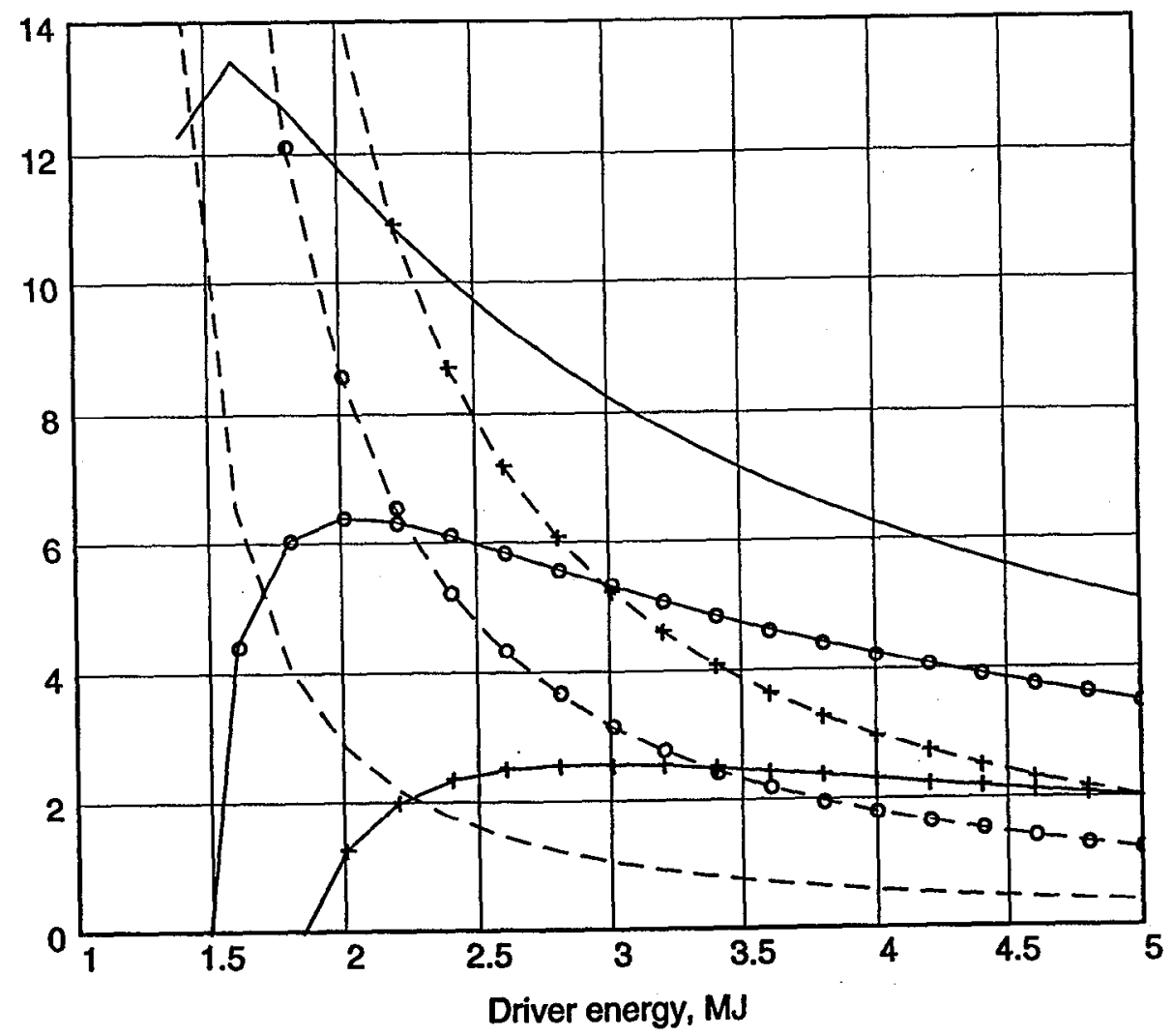

- 100 's $\$ / \mathrm{J}$ for Pnet $=100 \mathrm{MWe}$

$\rightarrow 100$ 's $\$ / \mathrm{J}$ for Pnet $=300 \mathrm{MWe}$

+ 100 's $\$ / \mathrm{J}$ for Pnet $=500 \mathrm{MWe}$

- - Rep-rate for Pnet $=100 \mathrm{MWe}$

-o- Rep-rate for Pnet $=300 \mathrm{MWe}$

+- Rep-rate for Pnet $=500 \mathrm{MWe}$ 
E3 $:=2.2,2.4 . .5$

Fig. 6. Allowable laser driver total cost (100's $\$ / J)$ and rep-rate $(\mathrm{Hz})$ for: Total Demo cost $=\$ 3 B$

Target $\alpha=1,2,3$

Driver efficiency $=7 \%$

Net power $=300 \mathrm{MWe}$

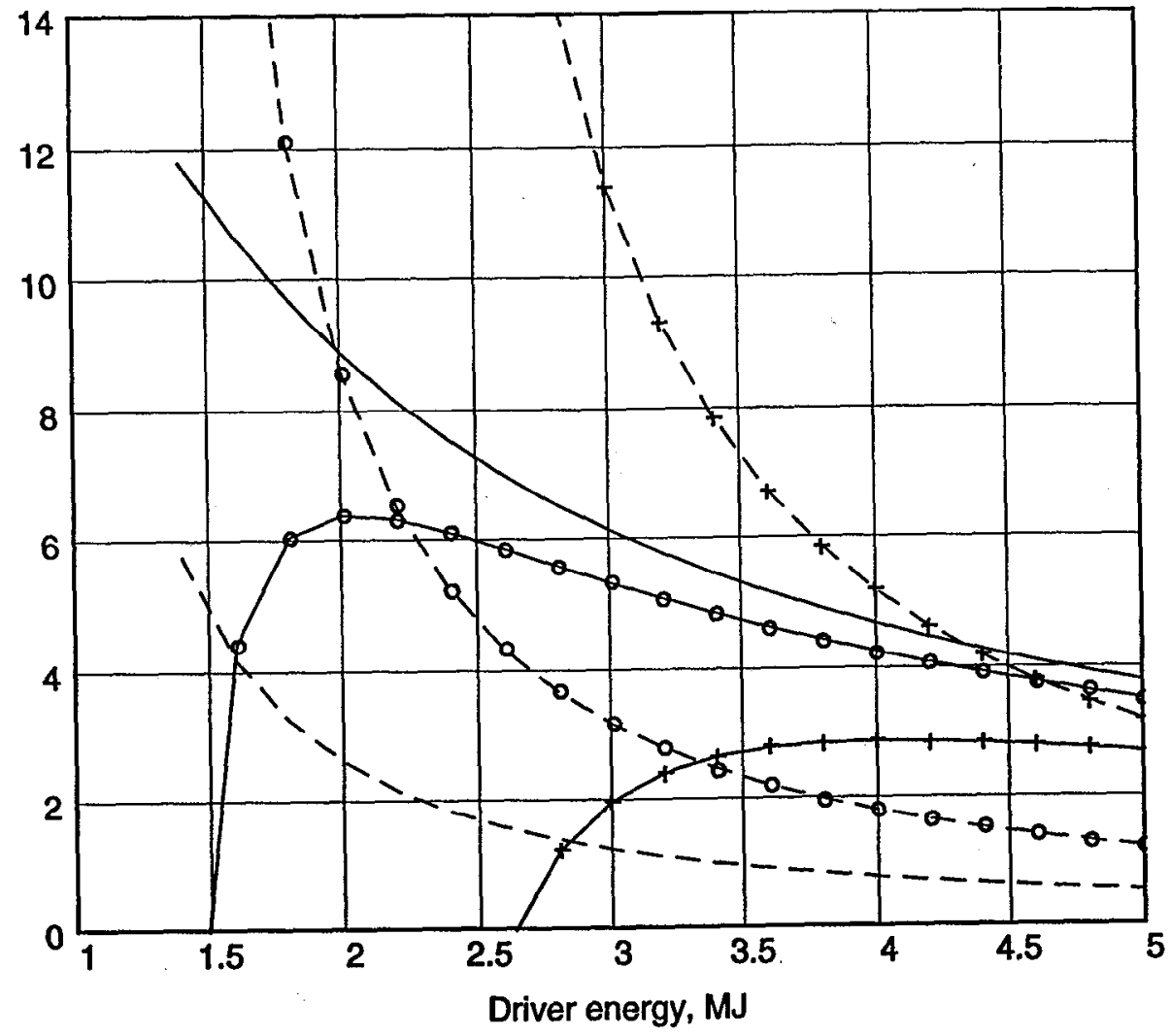

-100 's $\$ / \mathrm{J}$ for alpha $=1$

$\rightarrow 100$ 's $\$ / \mathrm{J}$ for alpha $=2$

- 100's $\$ / \mathrm{J}$ for alpha $=3$

- Rep-rate for alpha $=1$

$\rightarrow$ - Rep-rate for alpha $=2$

+- Rep-rate for alpha $=3$ 
Fig. 7. Allowable laser driver total cost (100's $\$ / J)$ and rep-rate $(\mathrm{Hz})$ for:

Total Demo cost $=\$ 3 B$

Target $\alpha=2$

Driver efficiency $=5,7,10 \%$

Net power $=300 \mathrm{MWe}$

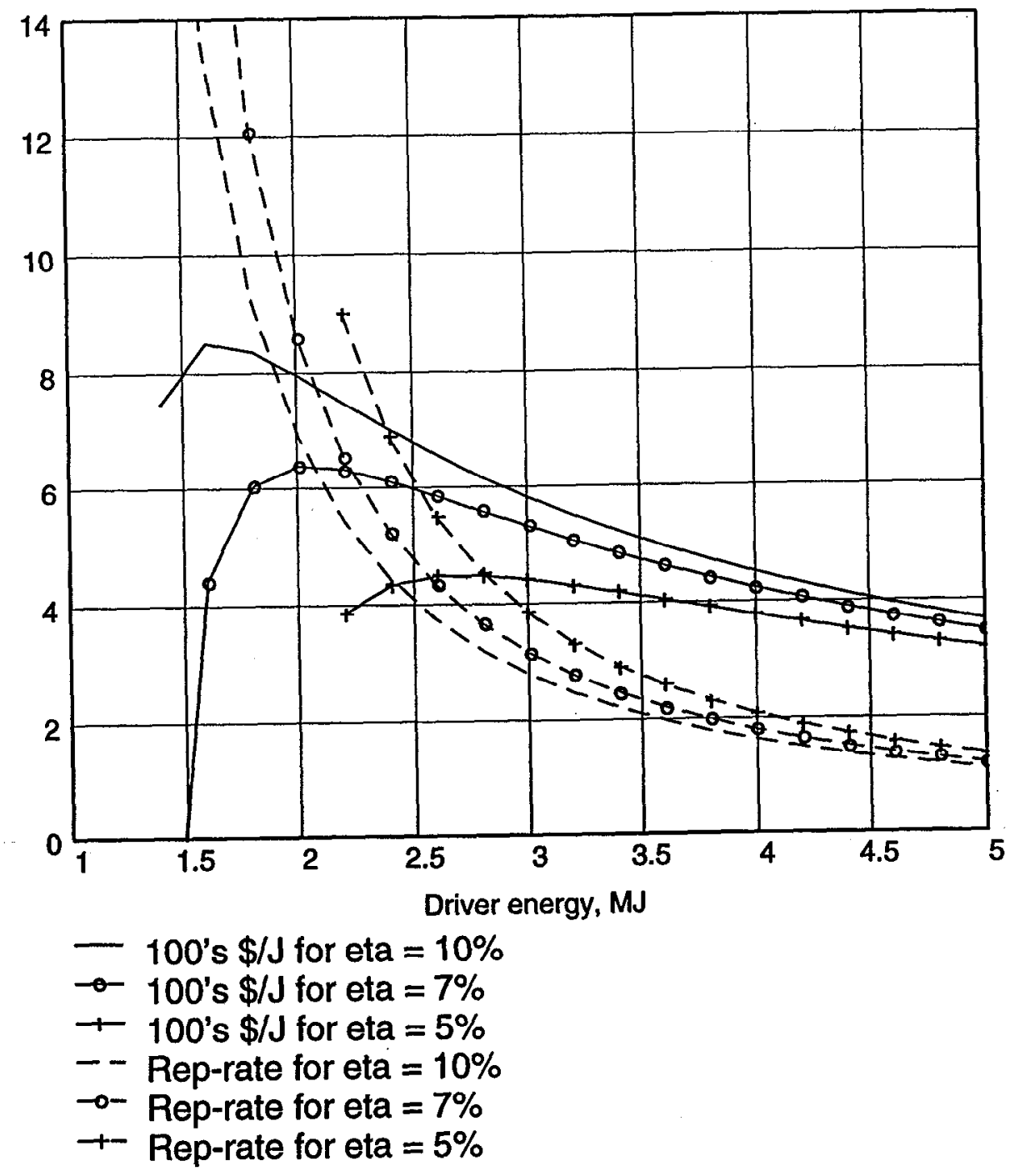


$E 4:=1.4,1.6 \ldots 5$

Fig. 8. Allowable HIB driver total cost (100's $\$ / J)$ and rep-rate $(\mathrm{Hz})$ for: Total Demo cost $=\$ 3 B$

Target $=$ heavy ion base case

Driver efficiency $=20 \%$

Net power $=100,300,500 \mathrm{MWe}$

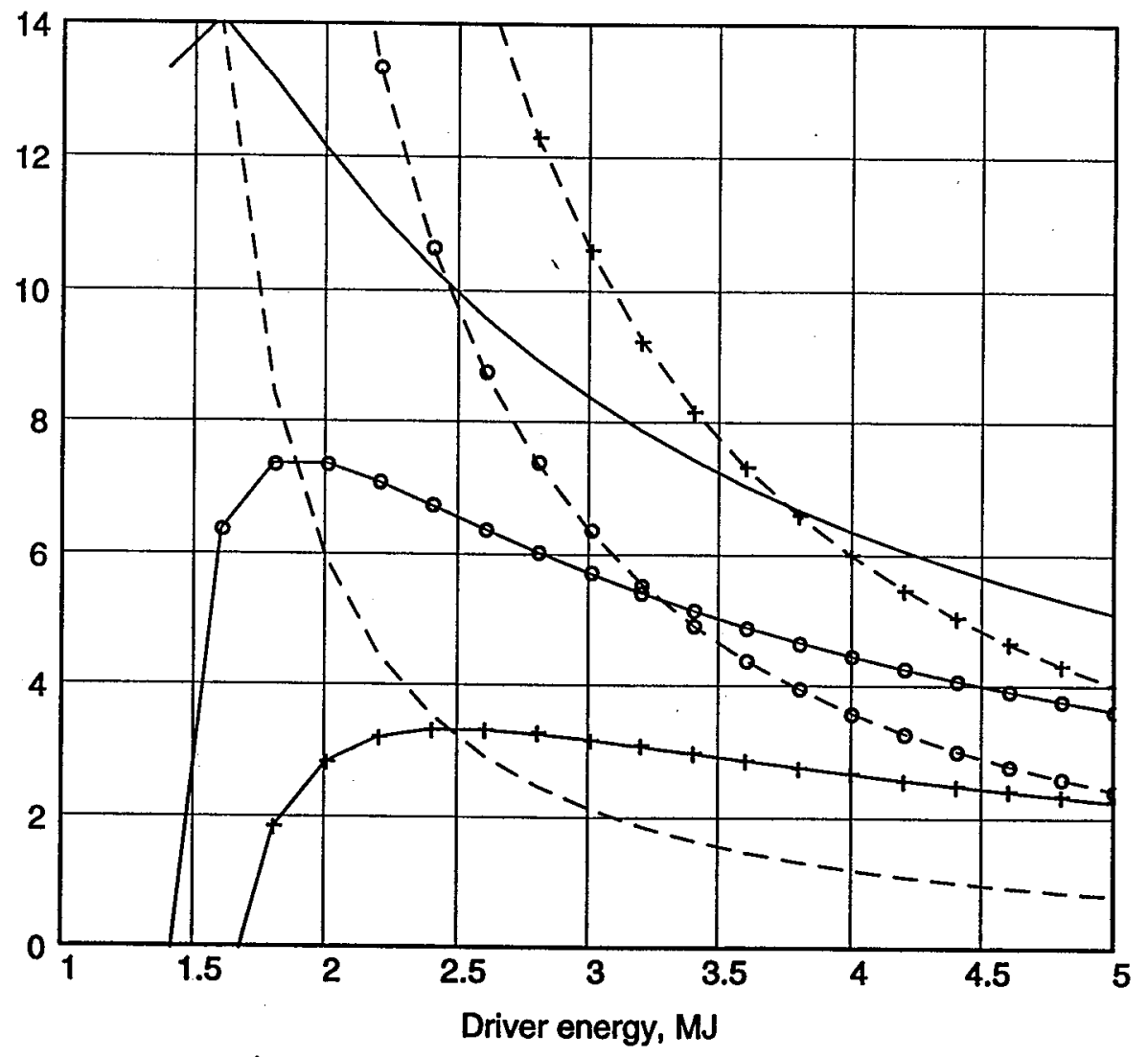

- 100 's $\$ / \mathrm{J}$ for Pnet $=100 \mathrm{MWe}$
- 100 's $\$ / \mathrm{J}$ for Pnet $=300 \mathrm{MWe}$
- 100 's $\$ / \mathrm{J}$ for Pnet $=500 \mathrm{MWe}$
- Rep-rate for Pnet $=100 \mathrm{MWe}$
- Rep-rate for Pnet $=300 \mathrm{MWe}$
+- Rep-rate for Pnet $=500 \mathrm{MWe}$ 
Fig. 9. Allowable HIB driver total cost (100's $\$ / J)$ and rep-rate $(\mathrm{Hz})$ for: Total Demo cost $=\$ 3 B$

Target $=$ HIB base case and close-coupled

Driver efficiency $=20 \%$

Net power $=300 \mathrm{MWe}$

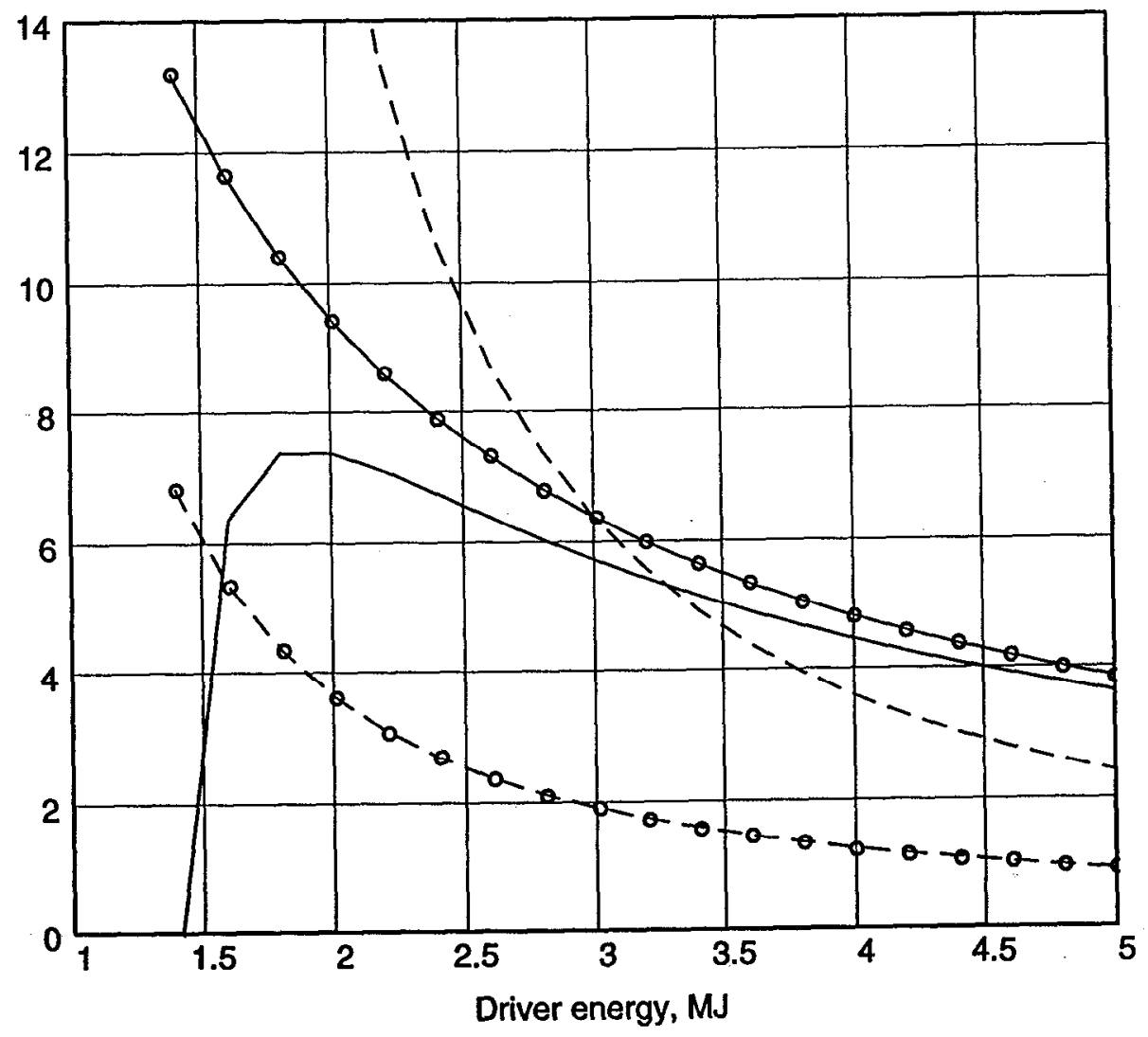

- 100 's $\$ / \mathrm{J}$ for base case gain

$\rightarrow 100$ 's $\$ / \mathrm{J}$ for close-coupled gain

- - Rep-rate for base case gain

$\rightarrow-$ Rep-rate for close-coupled gain 
Fig. 10. Allowable HIB driver total cost (100's $\$ / J)$ and rep-rate $(\mathrm{Hz})$ for: Total Demo cost $=\$ 3 B$

Target $=$ HIB base case

Driver efficiency $=15,20,30 \%$

Net power $=300 \mathrm{MWe}$

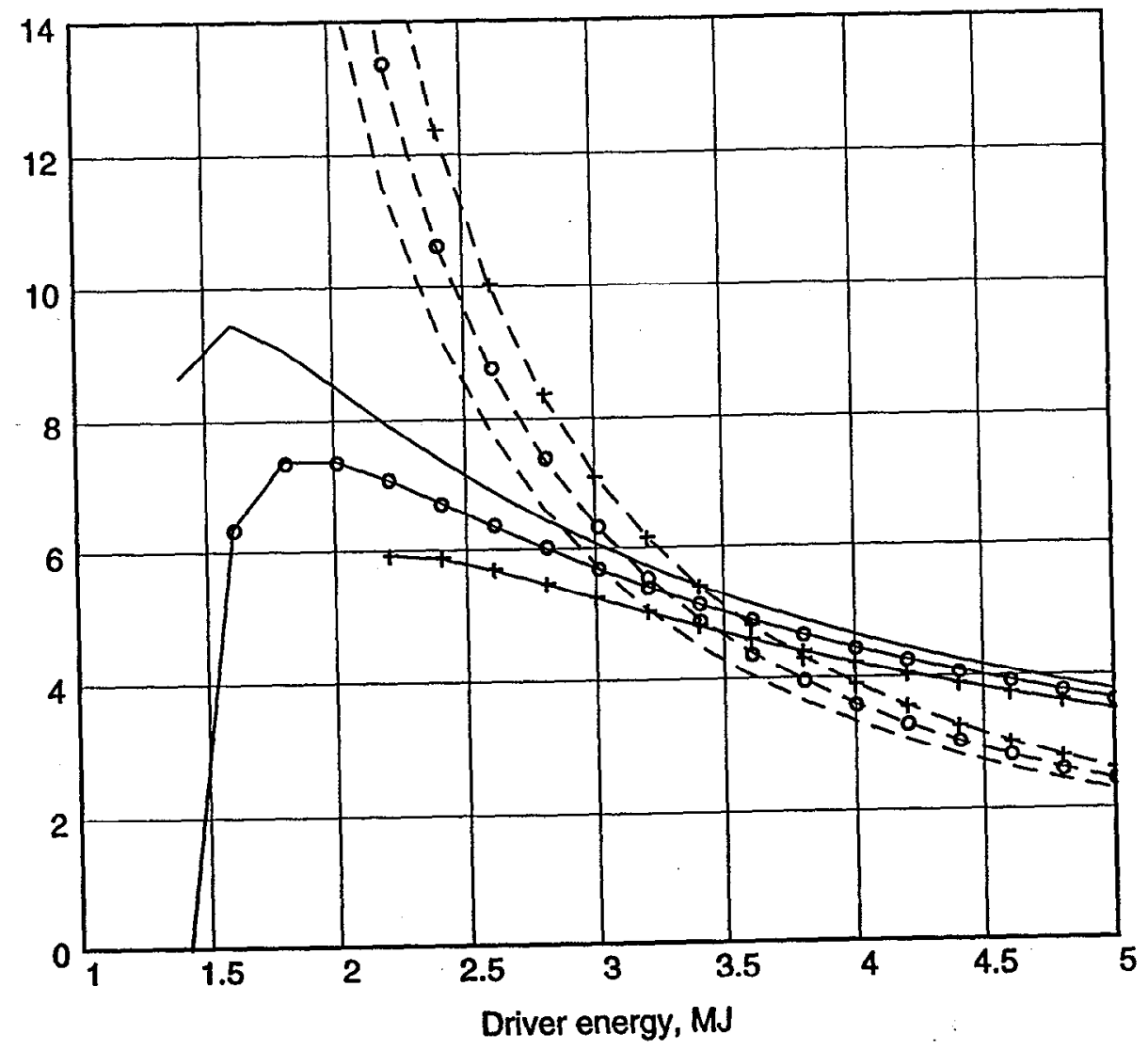

- 100 's $\$ / \mathrm{J}$ for eta $=30 \%$
- 100 's $\$ / \mathrm{J}$ for eta $=20 \%$
- 100 's $\$ / \mathrm{J}$ for eta $=15 \%$
- Rep-rate for eta $=30 \%$
- - Rep-rate for eta $=20 \%$
- Rep-rate for eta $=15 \%$ 
Find the driver energy needed for a particular yield goal for the ETF.

Egv := 2 guess value

$\operatorname{Eyg}(a, Y g o a l):=\operatorname{root}(Y(a, E g v)-Y g o a l, E g v)$

$Y g:=10,20 . .100$

Fig. 11. Driver energy required for a specified ETF yield goal

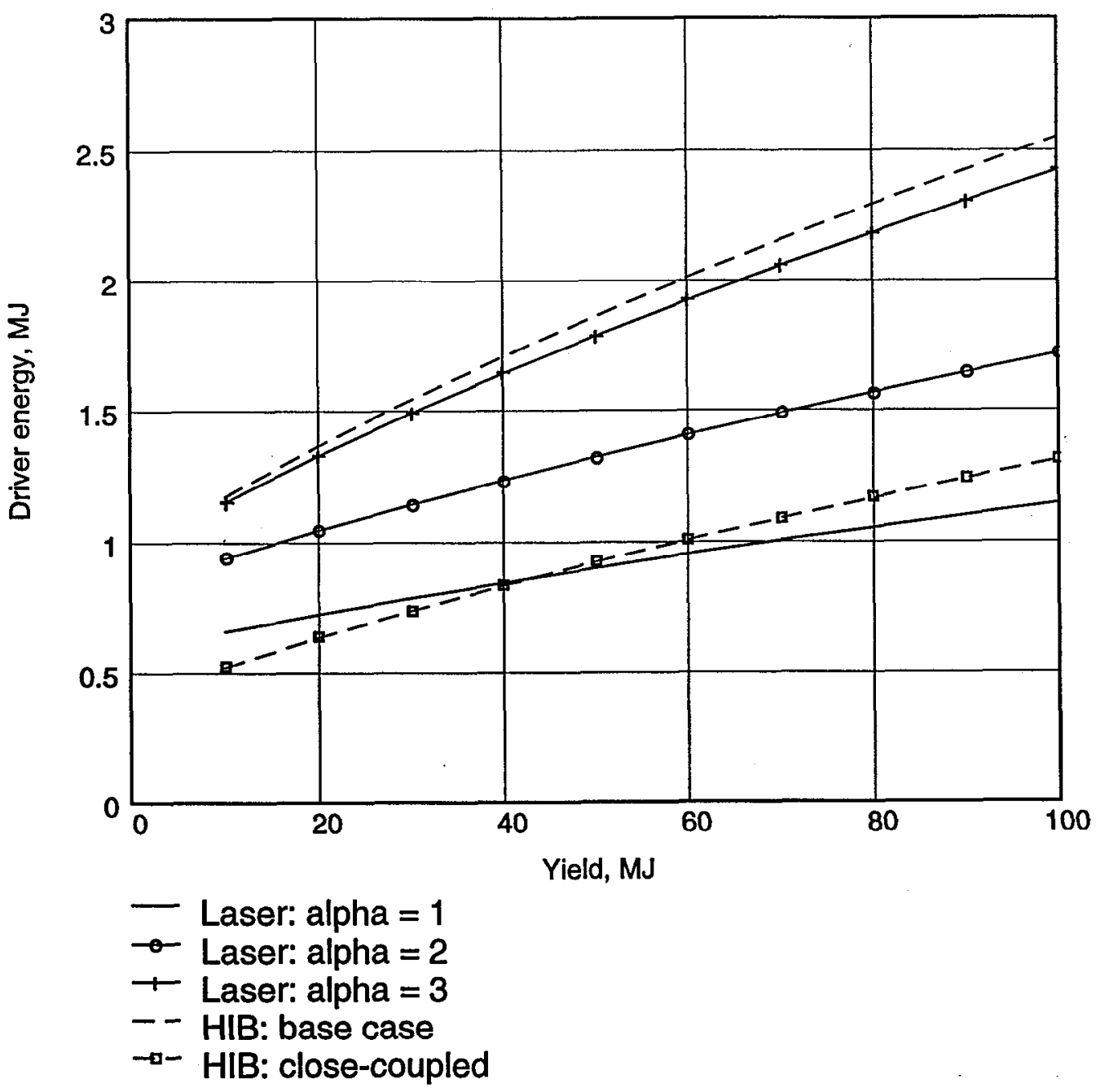


To find allowable driver cost for ETF, assume the following:

- Total cost $=\$ 2 \mathrm{~B}$

- Max rep-rate $=10 \mathrm{~Hz}$ so thermal power $=10^{*}$ Ygoal

- No electric power production

- Fusion chamber and heat transfer components costed at $\$ 1000 / \mathrm{kWt}=\$ 10 \% / \mathrm{MWt}$

Total allowable ETF driver cost

$\operatorname{CdETF}(a$, Ygoal $):=2 \cdot 10^{9}-\mathrm{UCfc} \cdot 10 \cdot$ Ygoal $\quad \operatorname{CdETF}(2,50)=1.5 \cdot 10^{9}$

Allowable driver cost expressed in 100's $\$ / \mathrm{J}$

$\operatorname{Cdpjy}(\mathrm{a}$, Ygoal $):=\frac{\operatorname{CdETF}(\mathrm{a}, \text { Ygoal })}{\operatorname{Eyg}(\mathrm{a}, \text { Ygoal }) \cdot 10^{6}} \cdot 0.01 \quad \operatorname{Cdpjy}(2,50)=11.34$

Fig. 12. ETF driver allowable total cost (100's $\$ / J)$ vs. yield per pulse for various target gain curves (assumes $10 \mathrm{~Hz}$ maximum rep-rate)

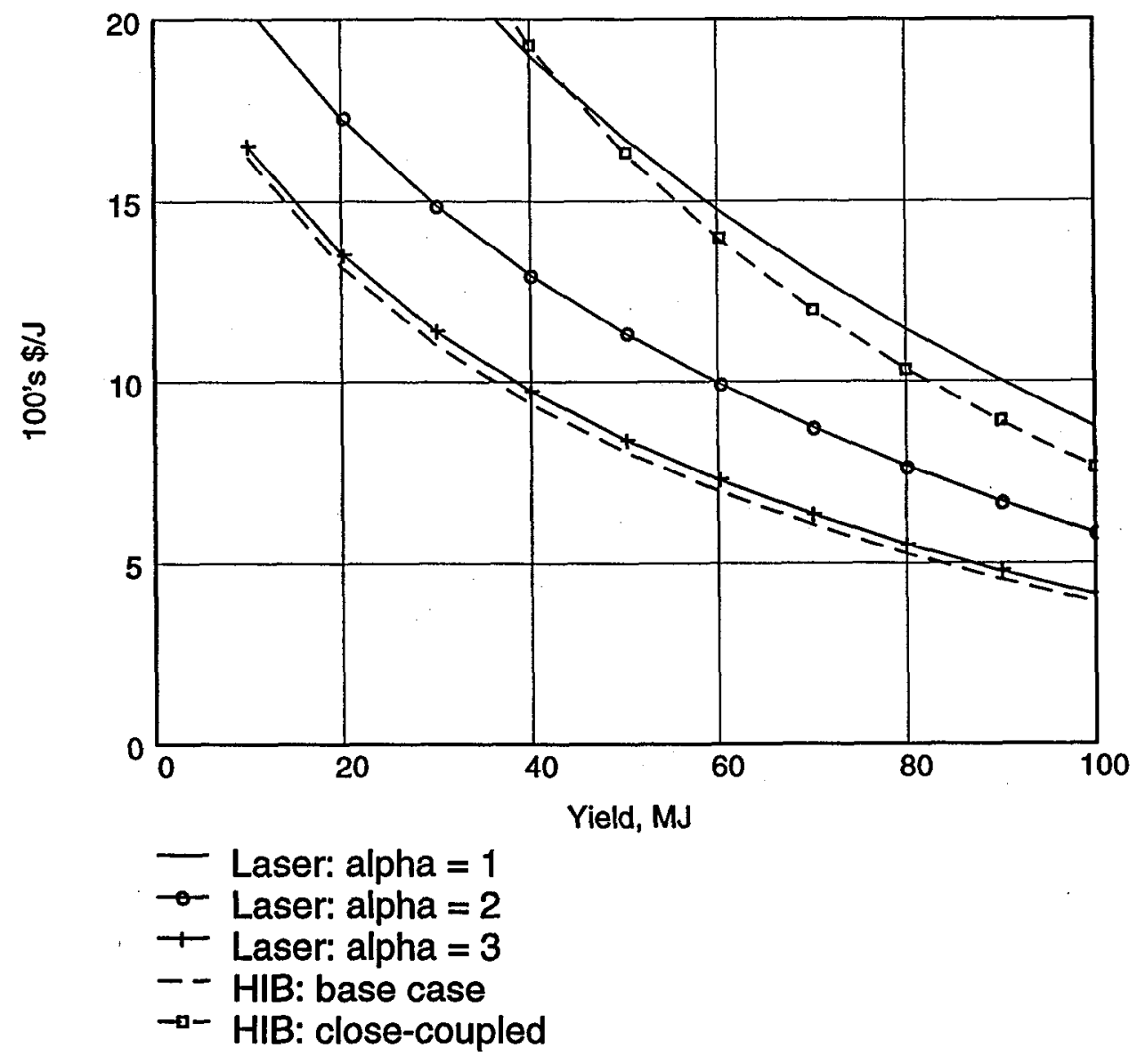


Cost of Electricity Calculation for Demo

Total Capital Cost, \$M (assumed goal)

$\operatorname{TCC}:=3 \cdot 10^{3}$

Annual O\&M Cost, \$M (assume fixed and not dependent on plant size for Demo. (This is about $2 x$ normal power plant scaling at the $500 \mathrm{MWe}$ size.)

$\mathrm{OM}:=100$

Ignore fuel costs and decommissioning costs

Constant Dollar Cost of Electricity, cents/kWeh

0.0966 = constant dollar fixed charge rate, $1 / y r$

$0.75=$ capacity factor

$8760=$ hours per year

$10^{5}=$ conversion of $\$ \mathrm{M}$ to cents and $\mathrm{MWe}$ to $\mathrm{kWe}$

$$
\operatorname{COE}(\mathrm{Pn}):=\left(\frac{0.0966 \cdot \mathrm{TCC}+\mathrm{OM}}{8760 \cdot 0.75 \cdot \mathrm{Pn}}\right) \cdot 10^{5} \quad \begin{aligned}
& \operatorname{COE}(100)=59.33 \\
& \operatorname{COE}(300)=19.78 \\
& \operatorname{COE}(500)=11.87 \\
& \operatorname{COE}(800)=7.42
\end{aligned}
$$

